\title{
Pros y contras de Flipgrid en la enseñanza del inglés según estudiantes del máster de profesorado
}

\section{Juan Carlos Casañ-Núñez}

Grupo de Investigación TALIS, Dpto. de Didáctica de la Lengua y Literatura, Universitat de València, España, juan.casan@uv.es

\begin{abstract}
Resumen
La crisis del COVID-19 implicó el cierre de centros educativos en la mayor parte del mundo, y que las clases presenciales se convirtieran en clases a distancia. Flipgrid es una plataforma gratuita de comunicación asíncrona multimodal disponible en varios sistemas operativos. Esta herramienta puede ser beneficiosa en el aprendizaje en línea porque incrementa la presencia social y humaniza el entorno de aprendizaje. El objetivo de este estudio cualitativo era conocer cuáles eran las ventajas e inconvenientes de Flipgrid para la enseñanza de inglés a distancia según 37 estudiantes de un máster universitario en formación de profesorado (especialidad de inglés). Los informantes consideraron que ofrece ventajas como la gratuidad, su atractivo para estudiantes jóvenes y la posibilidad de prácticar la expresión e interacción orales. Asimismo, indicaron algunas limitaciones, tales como que puede resultar inapropiada para personas tímidas, y que puede generar un volumen de vídeo que resulte abrumador para el profesor/a.
\end{abstract}

Palabras clave: Flipgrid, enseñanza a distancia, inglés como lengua extranjera

\section{Introducción}

La pandemia del COVID-19 tuvo un gran impacto en la educación. En primer lugar, suposo el cierre de escuelas y universidades en todo el mundo. Según Strauss (2020), el 6 de abril de 2020 el $90 \%$ de las instituciones educativas del planeta estaban cerradas. La segunda consecuencia fue que las clases presenciales se transformaron en clases en remoto. En la enseñanza a distancia los/las estudiantes pueden sentirse solos (Bartlett, 2018; Holbeck \& Hartman, 2018). Sin duda, esta sensación pudo verse reforzada por las medidas de restricción de la movilidad implementadas para frenar la propagación del virus. Varios 
autores consideran que Flipgrid puede ser beneficioso en el aprendizaje en línea porque incrementa la presencia social de los/as estudiantes (Bartlett, 2018; Saçak \& Kavun, 2019) y humaniza el entorno de aprendizaje (Craig, 2019).

Flipgrid (https://info.flipgrid.com/) es una plataforma de comunicación asíncrona multimodal disponible de forma gratuita en los principales sistemas operativos (Windows, Android, Mac, etc.). Básicamente, el/la profesor/a crea un panel (grid) para su clase y dentro añade una tarea o pregunta (topic). Los temas pueden incluir recursos multimodales como texto, audio, imágenes, vídeo. Los/as estudiantes pueden responder de forma multimodal a la tarea y también a las respuestas de los/as compañeros. De acuerdo con la página web oficial de la plataforma, se usa en más de 180 países y por más de 10000 educadores/as (https://info.flipgrid.com/).

Flipgrid es una plataforma reciente y todavía hay pocos estudios sobre ella. La pregunta de investigación de este trabajo cualitativo era la siguiente: según los/as estudiantes del máster universitario en formación de profesorado de la especialidad de inglés como lengua extranjera, ¿cuáles son las ventajas y limitaciones de Flipgrid en la enseñanza de lenguas extranjeras a distancia?

\section{Método}

Participaron 37 estudiantes (27 mujeres y 10 hombres) del Máster Universitario en Formación del Profesorado de Educación Secundaria Obligatoria, Bachillerato, Formación Profesional y Enseñanza de Idiomas (especialidad de inglés) de una universidad pública española con docencia presencial. La selección de la muestra fue por conveniencia (Dörnyei, 2007, pp. 98-99). El estudio tuvo lugar días después de que el Gobierno de España declarara el Estado de Alarma el 14 de marzo de 2020. Con la triple finalidad de crear un clima de aprendizaje favorable a la adquisición de nuevos conocimientos en la clase virtual, familiarizar a los estudiantes con una herramienta adecuada para la enseñanza remota, y conocer la opinión de los estudiantes sobre Flipgrid, se diseñó una actividad lúdica asíncrona en Flipgrid. Después de esta actividad, se pidió a los estudiantes que indicaran ventajas y limitaciones de la plataforma Flipgrid. Las respuestas se recogieron a través de una tarea escrita del Aula Virtual de una asignatura del Máster en Formación del Profesorado. Las datos se analizaron mediante dos técnicas. En primer lugar, se introdujeron en WordStat 8.0.29 y se crearon nubes de palabras para visualizar qué términos aparecían con mayor frecuencia y obtener una visión global. A continuación, se utilizó una técnica sugerida por Dörnyei (2003, p. 117) para el análisis de datos cualitativos. 
Primero, se buscaron ideas relevantes en las respuestas de los participantes. Luego, se construyeron categorías más extensas que englobaron esas ideas.

\section{Resultados}

En las figuras 1 y 2 pueden observarse las nubes de ideas de las respuestas sobre los aspectos positivos y negativos de Flipgrid. En la Figura 1 (ventajas) los términos más frecuentes son Flipgrid, tool, learning, class, app, classroom, English, videos, interesting y speaking. En la Figura 2 (limitaciones) las palabras más repetidas son students, app, bit, disadvantage, slow, tool, video, videos, feel, classroom y shy.

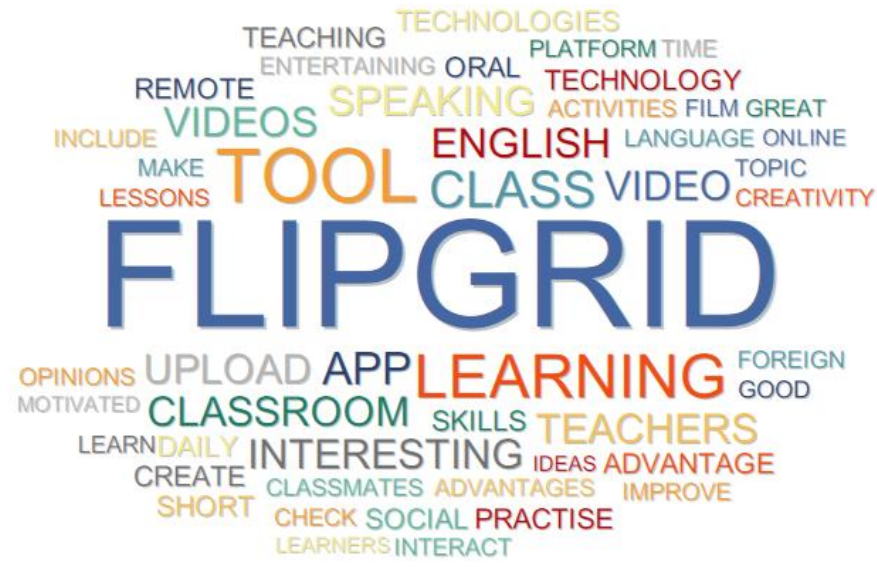

Figura 1. Nube de palabras de las respuestas sobre las ventajas de Flipgrid.

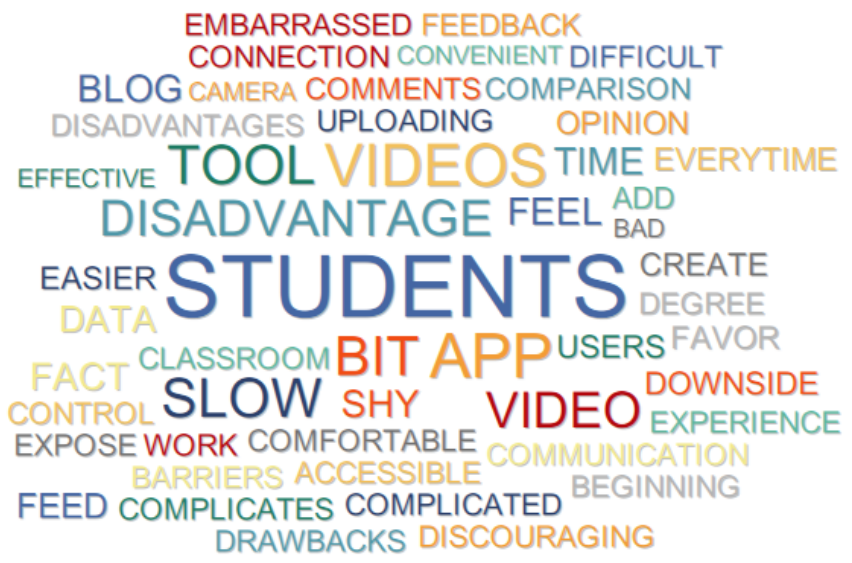

Figura 2. Nube de palabras de las respuestas sobre las limitaciones de Flipgrid.. 
En relación con los beneficios de Flipgrid, se extrajeron las siguientes ideas de las respuestas escritas de los informates: (1) es gratuita, (2) se puede utilizar en el aprendizaje remoto, (3) es atractiva para los adolescentes porque parece una red social y se puede usar con el móvil, (4) permite desarrollar la expresión oral, (5) posibilita practicar la interacción oral a través de las respuestas a los vídeos de los/as compañeros/as, y (6) permite a mantener el contacto con otros/as estudiantes a distancia. En cuanto a las desventajas de Flipgrid, se identificaron las siguientes categorías: (1) grabar vídeos puede ser problemático para las personas más tímidas, (2) la aplicación es lenta a la hora de subir los vídeos, (3) no es intuitivo cómo navegar y subir vídeos, (4) puede generar una cantidad de vídeo que resulte abrumadora para el/la profesor/a, y (5) puede haber problemas de privacidad. En relación con la primera limitación, es cierto que Flipgrid obliga a grabar un vídeo, pero también que incorpora opciones para pixelar el vídeo grabado o añadir una pegatina que cubra el rostro. En cuanto a la segunda limitación, la lentitud podría haberse debido a las tensiones a las que fueron sometidas las conexiones a internet en España durante el confinamiento. En relación con la privacidad, depende sobre todo de la configuración que haya elegido el creador de la tarea (grid).

\section{Conclusión}

El objetivo de este estudio era conocer las ventajas y limitaciones de Flipgrid en la enseñanza del inglés como lengua extranjera a distancia, según los/as estudiantes del máster en formación de profesorado (especialidad de inglés). Después de utilizar la plataforma, los participantes consideran que Flipgrid ofrece una serie de ventajas, tales como la gratuidad, su atractivo para estudiantes jóvenes y la posibilidad de prácticar la expresión e interacción orales. Asimismo, consideran que tiene varias limitaciones, entre ellas, que puede resultar inadecuada para estudiantes tímidos, y que el volumen de vídeo generado puede ser excesivo para el/la profesor/a. El estudio es limitado porque se basa únicamente en la experiencia de los/las participantes utilizando la plataforma. Dado que existen pocos estudios sobre Flipgrid, y que es potencialmente útil para la enseñanza de idiomas a distancia, se sugiere realizar estudios experimentales para averiguar si tiene o no alguno de los efectos beneficiosos que señalan los/as informantes.

\section{Referencias}

Bartlett, M. (2018). Using Flipgrid to increase students' connectedness in an online class. eLearn, 9(12). https://elearnmag.acm.org/archive.cfm?aid=3236703 
Craig, M. (2019). Engaging Flipgrid : Three levels of Immersion. En E. Alqurashi (ed.), Handbook of Research on Fostering Student Engagement With Instructional Technology in Higher Education (185-210). IGI Global. https://doi.org/10.4018/978-1-7998-0119-1.ch011

Dörnyei, Z. (2007). Research Methods in Applied Linguistics. Oxford University Press.

Dörnyei, Z. (2003). Questionnaires in second language research: Construction, and processing. Lawrence Erlbaum Associates, Publishers.

Holbeck, R., \& Hartman, J. (2018). Efficient strategies for maximizing online student satisfaction: Applying technologies to increase cognitive presence, social presence, and teaching presence. Journal of Educators Online, 15(3), 91-95. https://doi.org/10.9743/jeo.2018.15.3.6

Saçak, B., \& Kavun, N. (2019). Rethinking Flipgrid and VoiceThread in the context of online collaborative learning theory. En E. Alqurashi (Ed.), Handbook of Research on Fostering Student Engagement With Instructional Technology in Higher Education (211-228). IGI Global.

Strauss, V. (2020, 6 de abril). Schools of more than 90 percent of the world's students closed during this pandemic. This graphic shows how fast it happened. The Washington Post. https://www.washingtonpost.com/education/2020/04/06/schools-more-than-90-percent-worldsstudents-closed-during-this-pandemic-this-graphic-shows-how-fast-it-happened/ 